$\begin{array}{cl}\begin{array}{c}\text { Revue } \\ \text { de lhistoire } \\ \text { des religions }\end{array} & \text { Revue de l'histoire des religions } \\ & \begin{array}{c}\text { Figures de Noé de Gilgamesh au Coran } \\ \end{array}\end{array}$

Noé dans la tradition syriaque. Une mer de symboles

Noah in the Syriac Tradition: A sea of symbols

Muriel Debié

\title{
OpenEdition
}

Édition électronique

URL : http://journals.openedition.org/rhr/8472

DOI : $10.4000 /$ rhr.8472

ISSN : 2105-2573

Éditeur

Armand Colin

Édition imprimée

Date de publication : 1 décembre 2015

Pagination : 585-622

ISBN : 978-2-200-93012-7

ISSN : 0035-1423

Référence électronique

Muriel Debié, "Noé dans la tradition syriaque. Une mer de symboles», Revue de l'histoire des religions

[En ligne], 4 | 2015, mis en ligne le 01 décembre 2018, consulté le 30 avril 2019. URL : http://

journals.openedition.org/rhr/8472; DOI : 10.4000/rhr.8472 
MURIEL DEBIÉ

École pratique des Hautes Études, Paris

\section{Noé dans la tradition syriaque Une mer de symboles}

L'histoire de Noé et du déluge présente dans la tradition syriaque historique aussi bien qu'exégétique des similitudes avec des interprétations juives mais aussi une originalité fondamentale. Exprimée par des poèmes - une des caractéristiques de la littérature syriaque -, l'exégèse de l'histoire noachique présente la particularité unique de faire du père des nations, paradoxalement, un proto-ascète et de l'arche un type non seulement de l'Église, comme dans d'autres traditions chrétiennes, mais un prototype du bâtiment église même. Ce sont quelques-uns de ces symboles et de ces interprétations typologiques que cet article essaie de faire émerger de la mer de textes syriaques consacrés à l'histoire de Noé.

\section{Noah in the Syriac Tradition : A sea of symbols}

The story of Noah and the Flood in the Syriac historical as well as exegetical tradition shows many similarities with Jewish interpretations and yet a strikingly original trend. Through the means of poetry - one of the main features of Syriac literature -, the exegesis of Noah's story is unique in presenting the father of nations, paradoxically, as a protoascetic and the ark not only as a type of the Church - as in other Christian traditions - but as a prototype of the church as a building. This article aims at making at least some of these symbols and typological interpretations emerge from the sea of Syriac texts devoted to the story of Noah. 
Noé occupe une place particulière dans l'histoire du salut telle qu'elle est racontée dans la Bible parce qu'il est le seul, avec sa famille, à avoir survécu au Déluge et à la disparition de l'humanité coupable. Mais il est en même temps une figure ambiguë parce que les raisons pour lesquelles il fut distingué de ses contemporains ne sont pas clairement explicitées par le texte de la Genèse qui mentionne seulement sa « justice », non pas absolue, mais « dans sa génération $»^{1}$. La dimension positive qu'il porte est aussi contrebalancée par son ivresse et la malédiction lancée contre Canaan, le fils de son fils Cham. Tout autant que l'événement majeur dont elle fut partie prenante, le Déluge, l'ambiguïté même de la figure de Noé ouvrit la voie aux interprétations. Parler de Noé, c'est évoquer le Déluge, mais aussi l'humanité condamnée, le petit reste de l'humanité sauvée que constituait sa famille, l'arche et les animaux qu'elle contenait, le corbeau et la colombe messagers, la nouvelle création partagée entre ses fils, le sacrifice à la sortie de l'arche, mais aussi son ivresse et la malédiction de Canaan. Chacun des épisodes de la saga noachique a fait l'objet dans les traditions de commentaires des religions du Livre d'interprétations concurrentes. Les exégèses ne sont en effet pas seulement des constructions internes à chaque religion, mais naissent aussi de l'interaction ou de la controverse interreligieuse, d'où la nécessité de les étudier de manière transversale comme y invite cet ouvrage.

L'étude fondatrice de Noé et du Déluge menée par J. Daniélou sur les textes de l'Ancien Testament jusqu'à ceux des Pères de l'Église a mis en évidence, à la fois l'importance dans la tradition chrétienne de la dimension typologique des différents éléments de cette histoire appliquée au Christ, et la dimension eschatologique du Déluge $^{2}$. Si, déjà dans l'Ancien Testament, le Déluge est envisagé comme un événement passé, il est aussi interprété comme la figure d'un événement à venir. Comme le montre le livre d'Isaïe, l'anéantissement du peuple pécheur est annoncé, avec la promesse qu'en raison de sa fidélité à l'Alliance Israël sera épargné ${ }^{3}$. Au premier

1. Gen 6.8 .

2. Jean Daniélou, Sacramentum Futuri. Études sur les origines de la typologie biblique, Paris, 1950, chap. 2.

3. Daniélou, Sacramentum Futuri, p. 62, avec la référence à Es X, 16, XXIV, 1, 18, XXVIII, 14-18 et LIV, 8-9, mais aussi au Livre d'Énoch xci, 9 et cii, 1. 
déluge par l'eau doit succéder un second par le feu auquel seuls les justes seront soustraits. Ce second anéantissement par le feu qui apparaît déjà dans la littérature mésopotamienne 4 est repris dans une perspective eschatologique dans les traditions juives et chrétiennes. Comme le rappelle le patriarche Michel le Syrien dans sa chronique d'après Flavius Josèphe (au travers de la chronique d'Eusèbe) : « Adam avait prédit une double destruction, l'une par le feu, l'autre par le déluge $»^{5}$. Deux stèles furent érigées, l'une en pierre, l'autre en brique sur laquelle les fils de Seth écrivirent l'astronomie, pour que ces connaissances échappent à ces destructions. Un « livre des Séthiens » se trouve vraisemblablement derrière ces informations. Le jugement final par le feu est mentionné dans les épîtres de Pierre dans le Nouveau Testament et dans les commentaires patristiques ${ }^{6}$. Le déluge d'eau est interprété comme le type du déluge de feu du jugement dernier. À côté de cet aspect eschatologique, se développe en milieu chrétien une typologie sacramentaire du baptême : de même que Noé a affronté la mer de la mort qui a englouti l'humanité pécheresse, de même le baptisé descend affronter le dragon du mal dans les eaux de la piscine baptismale et en ressort vainqueur. Le Christ lui-même est un nouveau Noé, premier-né de la Création nouvelle après le passage par les grandes eaux de la mort ${ }^{7}$. Le Déluge est interprété par les Pères de l'Église comme la figure, l'antitype, du baptême (1 Pe 3,18) et l'arche comme celle de l'Église.

Deux types d'interprétation sont à l'œuvre dans la tradition chrétienne, l'une historique qui essaie de resituer Noé dans l'histoire du monde et de synchroniser l'histoire biblique avec celle des «nations », l'autre typologique, qui lit ces événements de l'Ancien Testament à la lumière du Nouveau et les replace dans une perspective eschatologique.

La tradition syriaque offre l'originalité d'être à la fois chrétienne et sémitique et présente la particularité par rapport aux traditions chrétiennes grecque ou latine d'avoir conservé nombre d'éléments interprétatifs d'origine juive et d'être ensuite passée dans les textes

4. Voir ici même la contribution de J.-J. Glassner.

5. Chronique de Michel le Syrien patriarche Jacobite d'Antioche (1166-1199), 4 vols. (vols I-III trad., IV texte), J.-B. Chabot, Paris, 1899-1924 (réimpr. Bruxelles, 1963 ; Gorgias Press, 2008). Désormais cité MS, I, 4, p. 3 T(exte), I, p. 5 V(ersion).

6. Daniélou, Sacramentum Futuri, p. 62 avec la référence à 2 P III, 3-10.

7. Daniélou, Sacramentum Futuri, p. 65-66. 
arabes chrétiens et souvent aussi musulmans. Elle joue donc un rôle de passeuse de motifs et de textes dans le domaine de l'exégèse biblique comme dans d'autres. Mais son rôle ne s'est pas limité à transmettre des strates juives au christianisme puis à l'islam. La tradition syriaque a aussi proposé ses propres interprétations, souvent originales par rapport à celle des exégètes de tradition latine et grecque. Elle l'a fait notamment sous la forme de poèmes qui sont une des grandes originalités de la pensée et de la théologie de langue syriaque : tout peut se dire et tout se dit sous la forme de poèmes qui sont un moyen de faire comprendre ce qui touche à la divinité, au moyen des images. Comme Dieu a utilisé les mots pour se rendre intelligible à la compréhension des hommes, semblables aux enfants dans leur faiblesse, de même le poète use de l'image des mots pour rendre perceptible l'invisible ${ }^{8}$.

Noé a si bien inspiré la tradition interprétative syriaque, qu'il n'est pas possible ici d'offrir une étude de chacun des textes produits, seulement de proposer une première synthèse des caractères originaux de cette tradition. Deux types de textes se sont particulièrement intéressés à la figure de Noé : les chroniques - qui tentent de le resituer dans l'histoire du monde depuis la création, telle qu'elle est racontée dans la Bible, et de l'ancrer par rapport aux chronologies des nations - et les commentaires exégétiques et patristiques. Les commentaires sur la Genèse sont tout naturellement le lieu où sont évoqués Noé et le Déluge, mais les hymnes liturgiques leur ont aussi fait une place?.

Éphrem le Syrien (m. 373), le plus connu sans doute des auteurs syriaques, qui vécut sur les zones frontières entre l'empire perse et l'empire romain, à Nisibe puis à Édesse, en Mésopotamie du nord, a le premier acculturé au christianisme de langue syriaque la figure noachique. Plusieurs de ses poèmes et son commentaire de la Genèse montrent tout le pouvoir interprétatif de l'histoire de Noé selon l'exégèse typologique caractéristique de l'école théologique d'Antioche ${ }^{10}$.

8. Voir Sebastian Brock, "Saint Ephrem the Syrian on Reading Scripture », The Downside Review 125 [438] (2007), p. 37-50. Bou Mansour, La pensée symbolique de Saint Éphrem le Syrien, Kaslik, 1988.

9. Laura Lieber, "Portraits of Righteousness. Noah in Early Jewish and Christian Hymnography », ZRGG 61.4 (2009), p. 332-355.

10. Son Commentaire sur la Genèse (désormais cité CGen) est le lieu principal où il interprète l'histoire de Noé. Sancti Ephraem Syri in Genesim et in Exodum commentarii, Raymond M. Tonneau (éd.), CSCO 152/Syr. 71 T, CSCO153/Syr. 
La tradition postérieure lui a ensuite largement emprunté. Et d'abord un texte apocryphe qui lui est parfois faussement attribué et qui porte le titre de La Caverne des trésors ${ }^{11}$. Il s'agit d'un texte composé en syriaque et plus tard traduit en géorgien, en copte et en arabe, qui relit l'histoire biblique selon un schème de six millénaires. Ce texte doit son titre à la mention d'une caverne située à proximité du Paradis où sont enterrés les patriarches d'avant le Déluge ainsi que les trois offrandes de l'or, de la myrrhe et de l'encens, qui seront ensuite apportées par les Mages à l'enfant Jésus. C'est un texte qui a été daté du début du $\mathrm{VI}^{\mathrm{e}}$ siècle ${ }^{12}$.

Aphraate, dit le Sage persan, qui écrivait au milieu du IV siècle dans l'empire sassanide, fait aussi référence à Noé dans ses Démonstrations (337-354) qui visent notamment à définir le christianisme et ses pratiques en regard du judaïsme. C'est donc dans un contexte de différentiation vis-à-vis du judaïsme que doit être lue son interprétation de l'histoire de Noé13.

D'autres auteurs se sont penchés sur la figure de Noé : Narsaï, qui, vers la fin du ve siècle, enseigna à l'École d'Édesse puis à celle de Nisibe, et appartenait à l'Église de l'Est, consacra deux de ses

72 V, Louvain : L. Durbecq, 1955 (section 5, p. 55 T, 43 V-50 T, 63 V et 6 après la sortie de l'arche, p. $63 \mathrm{~T}, 50 \mathrm{~V}-65 \mathrm{~T}, 52 \mathrm{~V}$ ). Son hymne principale sur Noé et l'arche est le madrashä Sur la foi 49 : Ephrem the Syrian. Select Poems : Vocalized Syriac Text with English Translation, Introduction and Notes, Sebastian P. Brock, \& George A. Kiraz (éds), Provo, Utah : Brigham Young U. P., 2006 ("Eastern Christian Texts", 2), p. 28-61. Plusieurs hymnes sur le Paradis et l'Église évoquent aussi Noé.

11. Su-Min Ri, éd. La Caverne des trésors : les deux recensions syriaques, CSCO 486-487/Syr. 207-208, Louvain : Peeters, 1987 (désormais cité Cav.).

12. Pour des études récentes du texte, voir Clemens Leonhard, «Observations on the Date of the Syriac Cave of Treasures », in : P.M.M. Daviau, J.W. Wevers \& M. Weigl (dir.), The World of the Aramaeans III : Studies in Language and Literature in Honour of Paul-Eugène Dion («Journal for the Study of the Old Testament, Supplement Series», 326) Sheffield : Sheffield A. Press, 2001, p. 255-293; Sergey Minov, "Syriac Christian Identity in Late Sasanian Mesopotamia : The Cave of Treasures in Context », Thèse, Jérusalem, 2013.

13. Irénée Hausherr, "Aphraate», in Dictionnaire de spiritualité ascétique et mystique, Paris : Beauchesne, 1937, p. 746-752 ; G.G. Blum, «Afrahat», in Theologische Realenzyklopädie, p. 625-635 ; Gorgias Encyclopedic Dictionary of the Syriac Heritage, Sebastian P. Brock, Aaron Butts, George A. Kiraz \& Lucas van Rompay, éds. Piscataway, NJ : Gorgias Press, 2011, désormais cité GEDSH, p. 24-25. Aphraatis Sapientis Persae Demonstrationes, Jean Parisot, éd., Paris : Firmin-Didot (Patrologia Syriaca 1.1), 1894 ; Marie-Joseph Pierre, Aphraate le sage Persan, Les Exposés II (Exposés XI-XXIII), Paris : Le Cerf, 1989 (« Sources chrétiennes », 359). La Démonstration 13 est celle qui évoque Noé en détail. 
longues homélies métriques (memrē) à sujets bibliques à Noé et à la bénédiction que Noé donna à ses fils ${ }^{14}$; Jacques de Saroug également (m. 521), qui appartenait, lui, à l'Église syro-orthodoxe et qui se forma à l'École d'Édesse, consacra un de ses memrē au Déluge ${ }^{15}$.

Ces traditions sont reprises en partie par les auteurs syriaques postérieurs qui ont composé des commentaires sur la Genèse : Théodore Bar Koni (fin $\mathrm{VIII}^{\mathrm{e}}$ s.), dans ses Scolies sur l'Ancien Testament ${ }^{16}$, et Ishodad de Merw (vers 850), dans son Commentaire de l'Ancien Testament ${ }^{17}$, présentent des interprétations similaires à celles du commentaire anonyme sur la Genèse copié dans un manuscrit de Diyarbakır, en Turquie, et conservé à Bagdad ${ }^{18}$. Un autre commentaire anonyme du Pentateuque, très proche des précédents, pourrait avoir été copié sur un modèle des années $900^{19}$. Des similitudes sont notables entre ces différents textes et les memrē d'Éphrem et de Narsaï sont des sources communes à ces commentaires syro-orientaux. Les hymnes réunis sans doute au $\mathrm{XIII}^{\mathrm{e}}$ siècle dans le Livre de Wardā, Le livre de la Rose, dans l'Église de l'Est, font aussi une place aux événements noachiques dans le contexte des catastrophes naturelles et des guerres contemporaines.

14. « Narsai », GEDSH, Lucas van Rompay, p. 303-304. J. Frishman, « The Ways and Means of the Divine Economy : An Edition, Translation and Study of Six Biblical Homilies by Narsai », Ph.D. diss., Univ. Leiden, 1992 : hom. 2, Sur le Déluge, p. 21-52 ; hom. 3, Sur la bénédiction donnée par Noé à ses fils, p. 53-68.

15. "Ya'qub of Serugh», GEDSH, Sebastian P. Brock, p. 433-435. M. Papoutsakis, «Jacob of Serugh. The Homily on the Deluge : Introduction, Translation, and Detailed Commentary », Ph.D. diss., Oxford, 2000 (n.v.).

16. "Theodoros bar Koni», GEDSH, Aaron M. Butts, p. 405-406. Il appartenait à l'Église de l'Est et enseigna à l'École de Kaškar. Théodore bar Koni. Livre des Scolies (recension d'Urmiah), Robert Hespel (éd.), CSCO 447-448/Syr. 193-194, Louvain : Peeters, 1983.

17. " Isho'dad of Merw», GEDSH, Lucas van Rompay, p. 216-217. Commentaire d'Išo 'dad de Merv sur l'Ancien Testament, I : Genèse, Ceslas van den Eynde (éd.), CSCO 126/Syr. 67 T, 156/Syr. 75 V, Louvain, 1955.

18. Lucas van Rompay, «Le commentaire sur Gen.-Ex. 9,32 du manuscrit (olim) Diyarbakir 22 et I'exégèse syrienne orientale du huitième au dixième siècle », in Symposium Syriacum, 1976, François Graffin \& Antoine Guillaumont (éds), Roma : PIO, 1978 (« Orientalia Christiana Analecta», 205), p. 113-123.

19. Préservé dans le manuscrit Mingana 553, qui pourrait avoir été copié au $\mathrm{XII}^{\mathrm{e}}$ siècle sur un modèle qui se trouvait à S1ırt, aujourd'hui perdu, et qui pourrait avoir daté des années 900. Abraham Levene, The Early Syriac Fathers on Genesis from a Syriac Ms. on the Pentateuch in the Mingana Collection. London: Taylor's Foreign Press, 1951 et $I d$., "Remarques sur deux commentaires syriaques de la Genèse (Le commentaire de Iš 'odad, évêque de Hadatta, et le manuscrit Mingana 553) », L'Orient Syrien 5 (1960), p. 55-62. 


\section{Le Déluge, ÉTAPe de L'Histoire du MONDE}

Dans la lignée de la chronique fondatrice d'Eusèbe de Césarée (vers 265-339), les chroniques universelles chrétiennes considèrent le Déluge comme un barreau signifiant de l'échelle du temps. Les années du monde sont comptées de la Création au Déluge qui en marque l'anéantissement. Des synchronismes chronologiques sont ensuite calculés du Déluge à un autre événement «mémorable» : la destruction du Temple de Jérusalem, Alexandre le Grand, la Nativité du Christ... Ce procédé de calcul des temps était compliqué pour les chroniqueurs chrétiens par le fait que les durées dans les versions hébraïque et grecque différaient de 656 ans pour la période pré-diluvienne ${ }^{20}$ et pour les auteurs syriaques par les durées encore différentes de la Pešittta, la plus répandue des versions syriaques de la Bible.

La Caverne des trésors, qui relit l'histoire du monde selon un schème de six millénaires, fait coïncider la fin du deuxième millénaire avec l'entrée de Noé dans l'arche, symbole du temps eschatologique de l'Église : « À l'heure où Noé entra dans l'arche, s'acheva le deuxième millénaire qui va depuis Adam jusqu'au déluge comme nous l'ont transmis les soixante-dix écrivains $»^{21}$.

\section{Le déluge biblique et les déluges des nations}

Le déluge raconté dans la Bible n'est pas le seul que connaissaient les historiens et ils tentèrent de situer chronologiquement le déluge biblique par rapport au déluge mésopotamien dont Xisuthrus était le héros, selon l'histoire reprise à Bérose, et le déluge grec situé du temps d'Ogygès ou de Deucalion. Eusèbe, qui le premier essaya dans sa chronique universelle de mettre en colonnes parallèles les chronologies à sa disposition, s'était heurté à la difficulté de synchroniser la chronologie biblique (dans la variété de ses versions), avec les milliers d'années de la chronologie babylonienne telle qu'il la connaissait au travers des Babyloniaca

20. Voir William Adler, Time Immemorial : Archaic History and its sources in Christian Chronography from Julius Africanus to George Syncellus, Washingtom : Dumbarton Oaks, 1989, p. 48.

21. Cav. 17, 22, en référence à la Septante. La recension orientale indique par erreur le troisième millénaire. 
de Bérose (vers 275 av. J.-C.) ${ }^{22}$. Il établit un parallélisme entre les dix générations prédiluviennes de la Bible et les dix rois ayant précédé le déluge sous Xisuthrus, de l'imminence duquel Bel/Zeus l'avait averti ${ }^{23}$. À l'histoire grecque, Eusèbe avait repris par ailleurs la mention du déluge du temps d'Ogygès, le prétendu fondateur d'Athènes et d'Eleusis, qui fut le premier homme en Attique et qu'il situe du temps de Moïse ${ }^{24}$. L'enjeu de ces datations était apologétique car il s'agissait de montrer l'ancienneté de la tradition biblique et le caractère récent de la civilisation grecque ${ }^{25}$. Eusèbe comme Éphrem s'interrogaient sur les compétences des Chaldéens et des Égyptiens en matière de chronologie.

D'Eusèbe, la mention et la datation de ces déluges est passée dans l'historiographie syriaque : par exemple dans la Chronique de Zuqnin jusqu'en 775 et surtout dans celle de Michel le Syrien (1126-1199. La chronique du patriarche Michel cite les sources d'Eusèbe de Césarée pour le passage concernant Xisuthrus : «Abydenos et Alexandre Polyhistor, philosophes païens, disent à propos de Noé et de l'arche : Chronos ayant révélé à Xisostros que le 15 du mois de juin surviendrait l'abondance des pluies et le débordement des eaux, celui-ci en entendant cela, s'en alla en navigant vers l'Arménie sur une barque fabriquée avec des planches. Elle se trouve encore là et procure des remèdes aux habitants $»^{26}$.

Quant au déluge des Grecs, Michel le Grand le situe en Thessalie du temps de Deucalion ${ }^{27}$. La Chronique de Zuqnin en revanche a repris à Eusèbe la mention du déluge du temps d'Ogygès, situé en l'an 258 d'Abraham ${ }^{28}$. Les chroniques se font donc l'écho des versions concurrentes du déluge dans les histoires des différents

22. Des Babyloniaca de Bérose - un clerc babylonien qui les écrivit en grec et les dédicaça au roi Antiochos Ir (281-261 av. J.-C.) - ne subsistent que des fragments et des citations chez les historiens anciens (Flavius Josèphe et Eusèbe) pour qui elles constituaient la source presque unique concernant l'histoire mésopotamienne. Voir Robert Drews, « Assyria in Classical Universal Histories », Historia 14 (1965), p. 129-142.

23. Aphraate mentionne aussi les dix générations pré-diluviennes, familières aux exégètes (Dem. 23, 4, Parisot, II, 13 ; Pierre, II, p. 885.

24. Die Chronik des Hieronymus, R. Helm (éd.), Berlin, 1956, Eusebius Werke, vol. 7 (GCS 47), 9, 31-34.

25. Adler, Time Immemorial, p. 19.

26. MS II, 1, IV, p. 7 T, I, p. 14 V.

27. MS III, 9, IV, p. 27 T, I, p. 47 V.

28. Incerti auctoris chronicon anonymum Pseudo-Dionysianum vulgo dictum, I, J.-B. Chabot (éd.), CSCO III, t. 1 T, Paris : E Typographeo Reipublicae, 1927 
peuples et entendent montrer l'ancienneté plus grande du déluge biblique par rapport aux déluges des «nations ».

Les chroniqueurs syriaques ont conservé une autre tradition interprétative, proche de celle du Livre des Jubilés (5, 1-10) et de 1 Énoch $(10,9)$, selon laquelle un premier châtiment du péché et de l'impureté de l'humanité était intervenu avant le déluge, plus exactement, selon Jacques d'Édesse, une destruction des géants rebelles (cf. Gen 6, 1-4) issus de la descendance des filles de Caïn qui avait transgressé l'alliance ${ }^{29}$. Dieu avait laissé ces géants - ou les hommes selon les chroniques de Michel le Syrien et de 1234 se détruire les uns les autres dans des guerres cruelles, au point que la terre se putréfia sous leur sang et devint stérile - c'est pourquoi Dieu aurait ordonné le déluge ${ }^{30}$ - et que leurs ossements formèrent de grands tells qui restèrent visibles jusqu'au déluge. Le déluge aurait ainsi effacé les traces de ce premier châtiment de la corruption de l'humanité - ou des géants - qui avait conduit à la stérilité de la terre. Le déluge du temps de Noé n'était donc que l'aboutissement d'une première destruction venue des hommes/géants eux-mêmes qui, de leur propre volonté, se livrèrent des guerres sans merci que Dieu permit mais ne suscita point. À la destruction de l'humanité - ou de l'humanité hybride des géants - par elle-même, succéda celle voulue par Dieu, qui n'épargna que Noé et sa famille.

\section{La chronologie noachique}

Les commentateurs se sont aussi intéressés à la chronologie du déluge et de la vie de Noé. La durée de la montée des eaux est de 40 jours et de 40 nuits selon le récit biblique de Gen 7, 17, mais Éphrem compte que l'arche flotta pendant 150 jours d'après Gen 7, $24^{31}$. Lui qui évoque les questions du calendrier naturel dans nombre de ses

(réimpr. CSCO 91, Syr. 43 T) ; J.-B. Chabot († 1948), CSCO 121/Syr. 66 V, Louvain : L. Durbecq, 1949.

29. Dirk Kruisheer, «Reconstructing Jacob of Edessa's Scholia », The Book of Genesis in Jewish and Oriental Christian Interpretation, J. Freshman \& L. Van Rompay (éds), Leuven, 1998 («Traditio Exegetica Graeca», 5), p. 187-196 (194-195). Voir Andy Hikens, « The Anonymous Syriac Chronicle up to the Year 1234 and its Sources », th. de doctorat, Ghent, 2014, chap. 4, p. 81-87.

30. MSI, 6, p. 5 T, I, p. $10 \mathrm{~V}$; II, 1, p. 7-8 T, I, 15-20 V.

31. Éphrem, CGen 61, 11. Tryggve Kronholm, Motifs from Genesis 1-11 in the Genuine Hymns of Ephrem the Syrian, with Particular Reference to the Influence of Jewish Exegetical Traditions, Uppsala : Almqvist \& Wiksell, 1978, p. 200. Le 
hymnes précise, sur la base de Gen 8,3 , que Noé resta 365 jours dans l'arche, du $17^{\mathrm{e}}$ jour du deuxième mois (Iyar) jusqu'au 27 du même mois l'année suivante (les mêmes dates sont données par Aphraate et par La Caverne des trésors notamment), "selon le calendrier lunaire », soient 365 jours. C'est l'occasion pour lui de nier que le calcul du nombre de jours de l'année était dû aux Chaldéens et aux Égyptiens, puisque du temps de Noé déjà il était connu ! ${ }^{32}$ Là encore la défense de l'ancienneté et de la supériorité des traditions bibliques explique cette remarque.

La question de la diminution de l'âge des patriarches à partir de Noé, de 900 ans environ jusqu'à 120 ans (Gen 6, 3) est évoquée par Éphrem et Aphraate : "Aux jours de Noé en effet, à cause de l'iniquité des hommes, il promit que les jours de l'homme ne seraient plus que de 120 ans. Il dit en effet : ils seront 120 ans sur la terre, mais c'est en l'an 600 de la vie de Noé qu'ils furent détruits : il leur ôta donc 20 ans $»^{33}$. Éphrem considérait comme une marque de l'amour de Dieu pour Noé le fait qu'il avait donné à Sem de vivre plus de 120 ans (comme d'autres patriarches post-diluviens d'ailleurs, mais qu'Éphrem n'évoque pas) ${ }^{34}$. Cent ans seulement s'étant écoulés entre l'annonce à Noé du déluge et l'entrée dans l'arche, certains commentateurs, comme Eusèbe, Éphrem et Aphraate expliquaient donc que Dieu avait retiré vingt ans, tandis que du côté syro-oriental, dans la lignée de Théodore de Mopsueste, le commentaire de Diyarbakır, Isho 'dad de Merw ou Théodore bar Koni estimaient que Dieu n'avait pas réduit le nombre d'années pour se repentir et que donc il avait dû parler à Noé en l'an 480 de sa vie et non en l'an $500^{35}$.

Aphraate a un long développement sur la chronologie de la vie de Noé par lequel il veut prouver à son lecteur que Noé ne s'était pas marié avant le déluge ${ }^{36}$ :

Et pour que tu saches qu'il en fut bien ainsi, je vais te le montrer à partir du calcul des années (...).

commentaire du ms. Mingana 553 mentionne aussi 190 jours au total mais comme durée du déluge (Levene, Early Syriac Fathers, p. 83).

32. Kronholm, Motifs from Genesis, p. 200.

33. Aphraate, Dem. 2, Parisot, I, 65 ; Pierre, I, p. 248.

34. Éphrem, CGen VI, 4, p. 56 T, 44 V.

35. Frishman, Ways and Means, p. 33, n. 73. Narsaï semble avoir suivi la tradition d'Éphrem car il dit que Dieu «plaça la limite au décret de leur vie » (v. 390), soit 100 ans.

36. Aphraate, Dem. 13, 6-8, Parisot, I, 552-557 ; Pierre, II, p. 595-598. 
À partir de cela nous pouvons savoir que Noé était âgé de 502 ans quand il engendra Sem, et de ce calcul on comprend que Noé n'avait pas pris femme avant que Dieu ait parlé avec lui [...]

En effet, s'il avait pris femme dans sa jeunesse, il aurait engendré des fils, comme Adam, qui engendra Seth à l'âge de 130 ans et Seth, à l'âge de 105 ans, engendra Enosh [...]

Quand il eut engendré trois fils, il commença à faire l'arche [...]

Il garda ses fils 97 ans, et il leur prit des femmes de la descendance bénie de ses pères $[\ldots]$

Et Noé entra dans l'arche à l'âge de 600 ans [...]

Noé et ses fils furent dans l'arche jusqu'à ce que soient passés douze mois et dix jours.

Aphraate, comme le montrent ces extraits, et La Caverne des trésors partagent cette chronologie et cette même idée que Noé n'avait pas pris femme avant que Dieu ne parlât avec lui. Il aurait donc pris femme la $502^{\mathrm{e}}$ année de sa vie, deux ans après que Dieu eût parlé avec lui, et il était âgé de 502 ans quand il engendra Sem. En l'an 600 de sa vie, il entra dans l'arche, selon Gen 7,6. Les informations concernant les générations des patriarches antédiluviens dans le livre de la Genèse constituent la source permettant d'établir la chronologie de la vie de Noé et de ses fils par rapport au déluge, dans le cadre de l'exégèse plus large concernant Noé et sa famille.

\section{La Figure de NoÉ}

La justification du salut de Noé et de sa famille dans sa génération ne reçoit pas d'explication claire dans le texte de la Genèse ${ }^{37}$. Certains textes rabbiniques estimaient même que Noé n'était pas digne de survivre au déluge et Yalkut Gen, $§ 44$ dit que Noé ne survécut que parce que Dieu avait prévu que Moïse descendrait de lui ${ }^{38}$. De la même manière, Aphraate mentionne qu'il fut éprouvé par Dieu pour que « le Messie, le vivificateur du monde, celui qui abolit les malédictions d'Adam soit enfanté de sa descendance ${ }^{39}$. Noé est ainsi justifié par sa postérité. Les commentaires juifs non bibliques

37. Voir Koltum Fromm, «Aphrahat and the Rabbis», p. 58-59 sur les interprétations de la justice de Noé.

38. Cité par Levene, Early Syriac Fathers.

39. Aphraate, Dem. 13, 6, Parisot, I, 556 ; Pierre, II, p. 597. 
expliquaient sa justice par ses bonnes œuvres et son comportement. La Lettre aux Hébreux dans le Nouveau Testament met l'accent sur sa foi qui était le fondement de sa justice : "Grâce à la foi, Noé, averti de ce qu'on ne voyait pas encore, prit au sérieux la parole de Dieu : il construisit une arche pour le salut de sa famille. Sa foi condamnait le monde et il reçut de Dieu la justice qui s'obtient par la foi $»^{40}$. Aphraate de même dit que « Noé parce qu'il a cru a été abrité du déluge $»^{41}$.

\section{Noé le juste et le chaste}

La tradition syriaque a développé une autre interprétation qui offre des parallèles avec les textes juifs, mais selon une autre perspective. Noé est présenté comme exceptionnel par rapport aux hommes de son temps et peut être qualifié de «juste» parce qu'il avait refusé de céder aux sirènes des filles de Caïn, la génération maudite, parce qu'il était resté intègre/chaste. Cette interprétation repose sur l'exégèse de deux passages de la Genèse. La première avait identifié dans Gen 6, 1-4 les « fils de Dieu » aux fils de Seth et « les filles des hommes » à la descendance de Caïn ${ }^{42}$. Les fils de Seth qui avaient d'abord vécu à proximité du Paradis étaient descendus s'unir aux filles de Caïn. Selon les termes d'Éphrem ${ }^{43}$ : « Ils furent détruits par les eaux d'en bas et celles d'en haut, selon ce qui a été dit : 'les profondeurs extrêmes vous ont appelés'». C'est le mélange de ces deux descendances des Fils de Dieu, assimilés aux Séthites devenus pécheurs, et des filles de Caïn, qui était considéré comme le péché d'origine qui avait corrompu l'état conjugal. Noé avait donc

40. He 11,7 .

41. Aphraate, Dem. 1, Parisot, I, 33 ; Pierre, I, p. 225.

42. Cette assimilation fut adoptée à partir de Julius Africanus dans la tradition chrétienne. Cf. Gedaliahu A.G. Stroumsa, Another Seed : Studies in Gnostic Mythology, Leiden : Brill (« Nag Hammadi Studies », 24), 1984 ; Jürgen Tubach, «Seth and the Sethites in Early Syriac Literature», in Eve's Children : The Biblical Stories Retold and Interpreted in Jewish and Christian Traditions, Gerard P. Luttikhuizen (éd.), Leiden - Boston : Brill («Themes in Biblical Narrative. Jewish and Christian Traditions », 5), 2003, p. 187-201; Pour ce thème dans la Caverne des trésors, Alexander Toepel, Die Adam- und Seth-Legenden in syrischen Buch der Schatzhöle. Eine Quellenkritische Untersuchungen, CSCO 618/Subs. 119, Louvain : Peeters, 2006 ; Helen Spurling \& Emmanuela Grypeou, « Pirke de-Rabbi Eliezer and Eastern Christian Exegesis », Collectanea Christiana Orientalia 4 (2007), p. 217-243 (p. 225, 227).

43. Éphrem, CGen 4, p. 59 T, 56 V. 
refusé de prendre femme et d'engendrer des fils pour éviter qu'ils ne se corrompent avec les filles de Caïn ${ }^{44}$. Le libre arbitre dont Noé a usé en faisant ce choix est érigé par Éphrem en modèle de celui dont jouissent tous les hommes : «Prends de Noé l'exemple, / car il peut réfuter / tous les contemporains /qui, s'ils l'avaient voulu, / auraient pu prospérer. / La liberté humaine / était tout aussi forte / en eux que chez Noé ${ }^{45}$.

Les commentateurs syriaques pensaient que Noé avait volontairement observé la qaddishutā, c'est-à-dire l'abstinence de relations sexuelles ${ }^{46}$. L'interprétation chrétienne qui valorise le célibat s'est imposée dans la tradition syriaque, en s'appuyant aussi sur la lecture de l'histoire de Noé dans Mt 24, 37-39 : «L'avènement du Fils de l'homme ressemblera à ce qui s'est passé à l'époque de Noé. À cette époque, avant le déluge, on mangeait, on buvait, on se mariait, jusqu'au jour où Noé entra dans l'arche. Les gens ne se sont doutés de rien, jusqu'au déluge qui les a tous engloutis : tel sera aussi l'avènement du Fils de l'homme ». La dimension eschatologique du déluge est ici affirmée, où la nourriture, la boisson et les relations sexuelles sont associées à la vie licencieuse qui provoqua le déluge et annonce la fin des temps et le jugement des pécheurs. Le déluge marque la fin d'un monde, mais est aussi une figure du monde à venir.

Éphrem, dans le madrashā déjà évoqué, Sur la foi 49, fait allusion à «l'armure de chasteté », zaynā d-nakpūtāa, de Noé, qui l'a fait peser plus léger que les autres âmes dans la balance de la justice $^{47}$ :

Comme est splendide Noé, dont l'exemple a surpassé celui de tous ses contemporains : ils ont été pesés sur la balance de la justice

et ils ont manqué ; une seule âme, avec son armure de chasteté les a contrebalancés. Ils ont été noyés dans le Déluge parce que le plateau de la balance était monté, alors que dans l'arche Noé le chaste et le juste était élevé.

44. Cf. Ri, Commentaire, p. 594.

45. Éphrem, HEcc 3, 9, Brock, L'œil de lumière, p. 37.

46. Voir Daniel A. Machiela, "Noah Traditions », in Noah and his Books, p. 238-241 : «Abstinence on the Ark». S.P. Brock, L'œil de lumière, Abbaye de Bellefontaine ( « Spiritualité orientale », 50), 1991, p. 158-159.

47. Brock \& Kiraz, Ephrem the Syrian, p. 30-31. 
Dans son Commentaire sur la Genèse aussi Éphrem insiste sur cet aspect. Il interprète les eaux du déluge comme le moyen trouvé par Dieu pour éteindre le feu du désir : «Il ouvrit les cours d'eau d'en bas et d'en haut de manière à éteindre le feu qui était allumé et brûlait en eux. Les eaux, l'extincteur, enflèrent parce que le désir avait enflé comme le feu ${ }^{48}$. Si Noé a été sauvé, c'est parce qu'il a défendu sa chair et son esprit et a été le propre gardien de son âme : " [Noé] a préservé son esprit de peur qu'il ne soit noyé dans le désir. [Dieu] a préservé la chair [de Noé] de peur qu'elle ne soit noyée dans les eaux du déluge $»^{49}$.

La même mise en parallèle des eaux montantes du désir et des eaux du déluge est présente dans le madrashā 1 d'Éphrem Sur Nisibe. Une autre dimension est associée dans ces deux textes d'Éphrem, celle du rapport entre la sauvagerie du désir et celle des animaux :

Les bêtes qui habitaient avec Noé avec lui dans le refuge de bois ne lui causèrent pas de mal, de même que les désirs qui habitaient en lui ne causèrent pas de mal aux membres de son corps. Ne vous étonnez pas de ce que les lions qui habitaient avec lui ne l'aient pas estropié, mais étonnez-vous grandement que le désir brûlant dans ses membres ne l'ait pas blessé ; et ne vous étonnez pas de ce qu'aucune des lionnes qui se sont approchées de sa chair ne l'ait estropié, étonnez-vous plutôt de ce que le désir de la chair ne se soit pas approché de sa chair. Ne vous étonnez pas de ce que les animaux carnivores qui l'entouraient de tous côtés ne lui aient fait aucun mal, mais étonnez-vous plutôt de ce que ces femmes impures et obscènes qui l'avaient entouré de toute part ne lui aient fait aucun mal (...) [Dieu] a rendu obéissantes à [Noé] ces bêtes que lui-même ne pouvait rendre obéissantes, tandis que lui-même rendait obéissants les désirs qu'il était capable de rendre obéissants. ${ }^{50}$

Cette sauvagerie est domptée de manière commune par la continence qui est imposée aussi aux animaux dans l'arche. Éphrem développe ce thème dans la strophe 4 du premier madrashā Sur Nisibe :

Noé avait vaincu les vagues du désir / qui submergeaient de son temps les fils de Seth.

parce qu'il avait préservé sa chair des filles de Caïn, / son vaisseau a foulé le dos des vagues.

48. Éphrem, Éphrem, CGen Arm. (The Armenian Commentary on Genesis attributed to Ephrem the Syrian, E.G. Mathews (éd.), CSCO 572/Arm 24 T, CSCO 573/Arm. 25 V, Louvain, 1998), 4, p. 67 T, 63 V.

49. Éphrem, CGen Arm, 4, p. 67 T, 63 V.

50. Éphrem, CGen Arm, 4, p. 68-69 T, 63-64 V. 
parce que les femmes ne l'avaient pas souillé, / il a imposé la continence

lui-même aux animaux / qui dans l'arche étaient tous en couple.

l'homme marié a imposé la continence aux conjoints ${ }^{51}$.

Noé a été sauvé parce qu'il a été continent et vigilant face aux désirs. Cette abstinence est un argument qu'Éphrem oppose aux marcionites qui niaient qu'il y eût quoi que ce soit de bon dans l'histoire humaine avant la venue de Jésus ${ }^{52}$. Cette idée de la pureté sexuelle de Noé au sein d'une humanité licencieuse est très présente aussi dans Les Démonstrations d'Aphraate ${ }^{53}$, en particulier dans la Démonstration 13, intitulée «Du Sabbat $»^{54}$. Aphraate situe la question de l'innocence de Noé dans un contexte anti-judaïque où il explique que ce n'est pas l'observance du shabbat ou de la circoncision qui sauve. Noé n'est pas justifié par l'observance de la Loi, ni même par sa foi, mais par sa virginité, parce qu'il a conservé l'intégrité, l'innocence (tammìmutā).

Cette interprétation se rapproche des interprétations rabbiniques (Midrash Bereshit Rabbah) qui interprètent aussi Gen 5, 32 comme indiquant que Noé n'eut pas d'enfants avant ses 500 ans. Mais si pour les rabbins Noé n'eut pas d'enfants plus tôt, c'est parce que Dieu le rendit stérile afin que ses fils ne fussent pas corrompus : un « enfant » de moins de cent ans n'était pas, selon les traditions rabbiniques, jugé sur ses actes mais ceux de son père, or les fils de Noé avaient moins de cent ans quand ils entrèrent dans l'arche ${ }^{55}$. En réponse sans doute à ces interprétations juives, Aphraate s'oppose explicitement à l'interprétation d'une stérilité de Noé qui aurait été voulue par Dieu : «Si donc Noé avait pris femme avant que Dieu

51. Éphrem, CNis 1, 4 : Edmund BECK (éd.), Des heiligen Ephraem des Syrers Carmina Nisibena, I, CSCO 218-219, Syr. 92-93, Louvain : Secrétariat du CorpusSCO, 1961 ; Éphrem le Syrien, La Descente aux enfers. Carmina Nisibena, intr., trad. et notes Dominique Cerbelaud, Abbaye de Bellefontaine ( Spir. Or. », 89), p. 34 ; Brock \& Kiraz, Ephrem the Syrian, text 19, p. 222-245 (p. 231).

52. Éphrem, CGen Arm 4, p. 66 T, 62 V.

53. Aphraate, Dem. 1, 13 et 18. Parisot, I, col. 553 ; Pierre, II, p. 596-7.

54. Voir Naomi Koltun-Fromm, «Aphrahat and the Rabbis on Noah's Righteousness in Light of the Jewish-Christian Polemic », in The Book of Genesis in Jewish and Oriental Christian Interpretation, J. Frishman \& L. van Rompay (éds.), Louvain, 1997, p. 57-71. Daniel A. Machiela, «Some Jewish Noah Traditions in Syriac Christian Sources », in Noah and His Books, Michael E. Stone, Aryeh Amihay \& Ruth A. Clements (éds), Atlanta : Society of Biblical Literature («SBL Early Judaism and Its Literature », 28), 2010, p. 237-252.

55. Koltun-Fromm, «Aphrahat and the Rabbis », p. 60-61. 
ait parlé avec lui, il aurait engendré comme ses pères, car aucune stérilité ne le menaçait, puisqu'en ce temps-là les fils d'Adam avaient été bénis pour qu'ils croissent et se multiplient $»^{56}$.

Juifs et chrétiens cependant partagent l'idée que si Noé n'eut pas de fils plus tôt, c'était pour éviter qu'ils ne fussent corrompus : « Si Noé avait gardé l'intégrité, ce n'est pas parce qu'il craignait pour lui-même d'être mêlé à la descendance maudite de la maison de Caïn, mais qu' ayant pris femme, il engendre des fils et que ses fils ne transgressent la Loi en prenant femme dans cette descendance $»^{57}$.

La chasteté est donc valable aussi, selon les Pères syriaques, pour les fils de Noé puisqu'il ne prit pas femme pour eux avant le moment d'entrer dans l'arche afin qu'ils ne transgressent pas eux non plus la loi en prenant femme dans la descendance maudite de la maison de Caïn : "Quand il eut engendré trois fils, il commença à faire l'arche et il les prévint de ne pas prendre femme avant qu'il soit temps d'entrer dans l'arche de peur qu'ils n'aient des fils et que ceux-ci ne corrompent leurs chemins et ne puissent être sauvés. Il garda donc ses fils pendant 97 ans et leur prit des femmes de la descendance bénie de ses pères ».

On retrouve là une interprétation proche de celle des textes rabbiniques, sans mentionner pour autant la signification de l'âge des enfants. L'idée de la chasteté de Noé est si bien établie qu'on la retrouve dans la chronique de Michel le Syrien qui résume les éléments fondamentaux concernant Noé, à savoir sa justice et sa chasteté, et sa position dans le déroulement chronologique de l'histoire du monde ${ }^{58}:$ «En l'an 1666 naquit le juste Noé qui garda la chasteté pendant 500 ans comme il est écrit. D'après le syriaque [la version de la Peshițtā] il engendra après 502 ans. En l'an 358 de sa vie finit le deuxième millénaire, selon l'hébreu en l'an 344 ».

\section{Noé nouvel Adam et type du Christ}

L'insistance sur la chasteté est propre au christianisme et tend à faire de Noé un proto-ascète jusqu'à ce qu'il doive endosser le rôle de second Adam, père des peuples : "Quand il vit que Dieu lui disait "toi seul je te laisserai la vie sauve", alors il prit femme

56. Aphraate, Dem. 13, 7, Parisot, I, 555 ; Pierre, II, p. 596.

57. Aphraate, Dem. 13, 7, Parisot, I, 555 ; Pierre, II, p. 596.

58. MS I, 5, p. 6, T, I, p. $10 \mathrm{~V}$. 
afin d'avoir une descendance à partir de laquelle le monde serait rétabli et afin de devenir le père des justes et des pieux $\gg^{59}$. Noé est présenté ici comme un second Adam, père de l'humanité nouvelle. Paradoxalement, il doit renoncer à ce qui fait sa justice, la chasteté, pour prendre femme et engendrer l'humanité nouvelle. Mais il a «pris une femme de la descendance bénie et engendra Sem, le père des justes ». Il n'a renoncé à la chasteté que pour prendre une femme juste, de la descendance de Seth et non de celle de Caïn, et engendrer une descendance juste.

Comme souvent, les textes apocryphes aiment à donner des noms aux figures anonymes du texte biblique. C'est ce que fait La Caverne des trésors qui donne comme nom de la femme de Noé, Haykal, fille de Namosa, fille d'Hénoch. Or Haykal en syriaque, c'est le temple, l'église. Noé, en type du Christ, a donc épousé l'Église pour engendrer, en nouvel Adam, l'humanité nouvelle sauvée des eaux du Déluge et de la corruption du péché. Et le nom Namosa signifie la Loi, mère de l'Église.

Comme l'explique Jean de Dara dans son ouvrage sur le sacerdoce (tel qu'il est cité par Michel le Syrien), Noé est interprété aussi comme un type du Christ en tant que prêtre : «choisi comme l'instrument du grand mystère de la rénovation », il reçut le sacrement du sacerdoce comme Abel le juste. Son sacrifice est interprété comme une figure du mystère du sacrifice du Christ ${ }^{60}$.

\section{Noé l'homme du repos}

Les auteurs syriaques ont joué sur la racine du mot Noé $n w h$, qui signifie repos, paix. Noé est à la fois celui qui est calme et celui qui apporte le repos, le soulagement. Il apparaît dans les madrashē d'Éphrem Sur Nisibe comme celui qui a établi une grande maison de repos comme il convient selon son nom (repos) pour tous ceux qui se sont réfugiés dans l'arche ${ }^{61}$. Il est appelé aussi «l'homme de repos » par Aphraate ${ }^{62}$ ou encore par Narsai ${ }^{63}$. Il est aussi chez Narsaï celui qui apporte le répit ${ }^{64}$, de même que chez Gabriel du

59. Aphraate, Dem. 13, 7, Parisot, I, 556 ; Pierre, II, p. 597.

60. MS I, p. $10 \mathrm{~T}, 20-21 \mathrm{~V}$.

61. Éphrem, CNis $1,10$.

62. Aphraate, Dem. 23, 4, Parisot, II, col. 13 ; Pierre, II, p. 885.

63. Narsaï, memrā II, v. 200.

64. Frishman, Ways and Means, p. 29, n. 41. 
Qatar qui le désigne comme "celui qui donne le repos ${ }^{65}$. Il est celui qui a établi dans l'arche une paix paradisiaque (cf. Is 11, 6-9 et $65,25)$ entre les créatures. Comme au Paradis en effet, le lion et le taureau, l'agneau et le loup vivent en paix, de même que le serpent et la colombe, le moineau et l'épervier. Un parallèle est également établi par Éphrem entre la paix dans l'arche et celle qu'il souhaite dans les églises où les assemblées de paix doivent régner, ainsi que l'égalité des riches et des pauvres et d'où l'orgueil, la division et les conflits doivent être absents : "Béni soit le Calme qui nous a dépeint à l'avance les symboles du calme dans l'arche $»^{66}$.

\section{Noé, le héraut de justice}

Un autre thème, reposant sur la lecture de Gen 6,3 , est présent dans les commentaires juifs et dans les thèses gnostiques ${ }^{67}$ et se retrouve aussi dans la tradition syriaque : il s'agit de la tradition qui fait de Noé un héraut de justice. Pour les chrétiens, Noé est présenté ainsi d'après un passage de 2 Pe 2.5 : «Il n'a pas non plus épargné le vieux monde mais quand il a fait venir le déluge sur le monde des impies, il a protégé huit survivants, dont Noé qui proclamait ce qui est juste ». Noé est celui qui annonce pendant cent ans le déluge pour permettre à ses contemporains de se repentir mais qui n'est pas écouté ${ }^{68}$. Les auteurs syriaques ont insisté sur la longanimité de Dieu qui ne voulait pas détruire l'humanité mais lui accorda le temps de la repentance. Selon Éphrem, un délai supplémentaire de sept jours fut accordé par Dieu, durant lequel les portes de l'arche étaient restées ouvertes après que tout le monde eut embarqué69.

Narsaï dans son memrā sur Noé, développe tout particulièrement cette idée : «Et là il fut patient pour montrer / qu'il ne désirait pas détruire. / Cent ans de Grâce / ont crié comme un héraut ». Le héraut

65. Levene, Early Syriac Fathers, p. 81 V.

66. Éphrem, Eccl. 51. Edmund BECK (éd.), Des heiligen Ephraem des Syrers Hymnen de Ecclesia, CSCO 198-199/Syr. 84-85, Louvain : Secrétariat du CorpusSCO, 1960 ; Dominique Cerbelaud, Éphrem le Syrien. Le combat chrétien : Hymnes de Ecclesia, Bégrolles : Abbaye de Bellefontaine, 2004 («Spiritualité orientale », 83).

67. G.A.G. Stroumsa, Another seed. Studies in Gnostic Mythology, Leiden (Nag Hammadi Studies 24) p. 84.

68. Éphrem, CGen VI, 9, p. 59 T, 47 V ; Iš odad de Merw, CGen 114, 14-17 ; Kronholm, Motifs from Genesis, p. 181.

69. Éphrem, CGen VI, 10, p. 60 T, 47 V. 
chez Narsaï n'est pas Noé lui-même, mais le bruit des scies coupant le bois, la « voix de la fabrication de l'arche » invitant les vivants à demander aux morts pourquoi ils étaient eux aussi coupés. Les êtres muets, bois de l'arche et animaux, interpellent les êtres rationnels pour les inviter à se convertir : "Comme un héraut était la voix / de la production de l'arche qui criait $\gg^{70}$. Les animaux prennent en effet une place particulière dans ce schéma, leur rassemblement devant être compris comme un signe de l'appel à la repentance : «Dans tout cela le Créateur proclamait / la repentance aux oreilles des têtus, / dans la fabrication du bois de l'arche / et le rassemblement des animaux des champs. / Des révélations de cent ans / comme des trompettes retentissaient $»^{71}$. Selon Narsaï, les hommes, s'ils n'avaient pas compris le sens de la construction de l'arche, auraient dû être alertés par le fait que les animaux avaient quitté leurs lieux de vie. Il ajoute à la durée de cent ans pour la fabrication de l'arche, une durée supplémentaire de sept jours où Dieu rassembla les animaux de la création qu'il avait faite en sept jours :

Il plaça la limite à sept jours / jusqu'à ce qu'il ait assemblé les animaux

à la manière dont il avait façonné toute chose / et s'était reposé de ses travaux le septième jour $(\ldots)$

après une prolongation des années / Il fixa la limite à sept jours

car durant cent ans et sept (jours) / il avait attendu la repentance ${ }^{72}$.

Le thème des moqueries dont Noé est la victime pendant ce temps est présent dans la haggadah juive et apparaît aussi dans la tradition syriaque. Narsaï dit ainsi que les impudents se moquèrent de lui ${ }^{73}$. Dans son Commentaire sur la Genèse, Éphrem dit qu' « Ils travaillèrent et peinèrent à la tache de l'arche et [les autres] ne cessaient de se moquer de la délivrance de Noé $»^{74}$. Dans son madrashā Sur la Foi 56, 2 il fait allusion aussi aux moqueries dont l'accablaient «les fous ( $s k l$ ') et les méchants qui lui demandaient où était le déluge. Mais lui gardait le silence et ne polémiquait pas $(d r s ̌ s)$ car il ne lui avait pas été révélé qu'il n'aurait pas lieu avant 100 ans ». Ce passage met l'accent sur le fait que Noé n'était pas un

70. Narsaï, memrā II, v. 239-240.

71. Narsaï, memrā II, v. 380-386.

72. Narsaï, memrā II, v. 319-322 et 330-334.

73. Narsaï, memrā II, v. 249.

74. Éphrem, CGen VI, 9, p. 59 T, 49 V et CGen Arm 4, p. 65 T, 61 V. 
prophète et n'avait pas reçu de révélation sur le moment où aurait lieu le déluge. Il fut un serviteur obéissant en construisant l'arche mais pas un serviteur inspiré.

\section{L'ARCHE TYPE DE L'ÉGLISE}

Dans la tradition chrétienne, l'arche représente les mystères de l'Église ${ }^{75}$. C'est tout particulièrement vrai en syriaque où elle apparait comme une forêt de symboles. Deux termes sont employés pour la désigner : Éphrem utilise kewēlā, un terme qui est utilisé en Mt 24.38 dans la version de la Pešițta et dans Luc 17.27 dans la version de la Pešittta et de la Curetonienne. C'est le mot qibōtā en revanche qui est présent dans la version de la Genèse dans la Pešițta et dans la version de Mt 24.38 et Luc 17.27 dans le manuscrit Sinaïticus syr. C'est ce terme aussi qu'emploie Aphraate. Sebastian Brock suggère que l'usage de kewela peut s'expliquer par le souhait de distinguer l'arche de Noé de l'arche d'Alliance qui est appelée qibōtā ou arōna $\bar{a}^{76}$.

C'est pour le récit du Déluge que les liens entre Éphrem et La Caverne des trésors sont les plus manifestes ${ }^{77}$. Concernant l'organisation interne de l'arche et la répartition de ses locataires dans les trois étages, Éphrem dans le madrashā 2, 12 Sur le Paradis $^{78}$ et La Caverne des Trésors ${ }^{79}$ ont le même ordre que le fragment d'Hippolyte sur le Pentateuque ou les Pirke de Rabbi Éliézer $^{80}$, avec en bas le bétail, au milieu les oiseaux, en haut Noé et sa famille. Théodore Bar Koni ${ }^{81}$ et Isho' dad de Merw ${ }^{82}$ indiquent

75. Daniélou, Sacramentum Futuri, p. 80-84. Cav. 18.3. Bou Mansour, La pensée symbolique de Saint Éphrem, p. 317-318.

76. Brock \& Kiraz, Ephrem the Syrian, Select Poems, p. 31, n. 2.

77. Cf. Ri, Commentaire de la Caverne des trésors, p. 255.

78. Edmund Beck, Hymnen de Paradiso, p. 8 ; Sebastian Brock, Saint Ephrem : Hymns on Paradise, Creastwood, N.Y : St Vladimir's Seminary Press 1990, p. 89.

79. Cav. 14, 9 3. Helen Spurling \& Emmanuela Grypeou, «Pirke de-Rabbi Eliezer and Eastern Christian Exegesis », Collectanea Christiana Orientalia 4 (2007), p. 217-243 (p. 241).

80. Cav., 14,$9 ; 18,2$.

81. TBK, memrā II, trad. Scher p. 106, 3-5 ; trad. Hespel-Draguet, p. 120.

82. Isho'dad, CGen 6, 16, trad. Vosté et al., p. 118 ; trad. C. van den Eynde p. 127. 
un autre ordre, semblable à celui d'Origène ${ }^{83}:$ le bétail, les oiseaux et les hommes à l'étage supérieur, les animaux sauvages au milieu et les reptiles à l'étage inférieur, où la préoccupation est de montrer que Noé et sa famille sont séparés des animaux dangereux qui pourraient s'en prendre à eux.

Narsaï évoque la continence et l'ascétisme qui régnaient dans l'arche et la dimension eschatologique qui y est associée : "Le Signe a réconcilié les espèces entre elles et les a soumises à Noé. / Une grande paix régnait à la porte de la maison du Juste / et les espèces qui se consommaient les unes les autres / s'embrassaient les unes les autres avec amour $»^{84}$. Deux éléments rappellent ici la situation au Paradis : le fait que les animaux ne s'entredévorent pas dans l'arche et d'autre part le fait qu'ils sont soumis à Noé. L'auteur voit en cela la restauration de la souveraineté d'Adam sur les animaux qu'il nomma au Paradis mais qui lui échappèrent après la chute ${ }^{85}$.

La question de la nourriture et des besoins naturels des hommes et des animaux dans l'arche est ainsi ramenée à la situation au Paradis où tous étaient végétariens/végétaliens et en miroir de la fin des temps, lisant ainsi la situation dans l'arche selon une perspective eschatologique. La mention de la construction des réservoirs d'eau et des resserres pour la nourriture telles que les mentionne $L a$ Caverne des trésors par exemple est contradictoire avec le « vous ne mangerez ni ne boirez » plus loin dans le même texte ${ }^{86}$. Des questions très concrètes et matérielles furent en effet abordées concernant la nourriture et les déjections pendant l'enfermement. D'après le commentaire du manuscrit de Diyarbakır qui, à la manière des Hexaemeron, expose les connaissances contemporaines sur l'homme et la nature, explique que les hommes et les animaux dans l'arche ne produisaient pas d'excréments qui les auraient autrement asphyxiés ${ }^{87}$. L'auteur du commentaire explique qu'une sorte de sommeil s'était emparé de tous, entraînant la suspension des besoins naturels. Il mentionne que d'autres commentateurs disaient qu'hommes et bêtes

83. Pour Origène, voir Spurling \& Grypeou, "Pirke de-Rabbi Eliezer», p. 242.

84. Narsaï, memrā II, v. 303-305.

85. Narsaï, memrā II, v. 314-317.

86. Cav. 4,10 et 16.17 .

87. p. 58-59 T, 74-76 V. 
mangeaient. L'arche était sans lumière, mais de l'air circulait pour atténuer les odeurs. Ses occupants buvaient l'eau du dedans ou du dehors : les eaux primordiales ayant été créées douces n'étaient pas encore salées. Ce passage est l'occasion d'exposer les croyances alors répandues sur la salinité des eaux ${ }^{88}$. Selon Narsaï, des réserves de nourriture furent emmagasinées, mais à peine suffisantes pour la subsistance des corps : ce n'était pas une nourriture « de satiété » ${ }^{89}$. La dimension de l'ascèse est mise en avant.

\section{Le capitaine de l'arche}

L'arche étant un navire, les commentateurs se sont demandés qui en était le capitaine ou le navigateur ${ }^{90}$. Le pilote de l'arche était, selon Éphrem, l'ange de Dieu. Cette tradition est reprise dans la Chronique de $1234^{91}$. Elle est développée aussi dans La Caverne des trésors: l'ange du Seigneur se tenait au sommet de l'arche comme son pilote (18.14) pour lui faire parcourir son trajet selon le symbole de la Croix (19.5). Le bois dont elle était faite aurait été coupé sur les pentes du Paradis. Chez Narsaï, c'est le Signe de Dieu qui est le marin et le Commandement le capitaine, selon une lecture symbolique ${ }^{92}$ :

Le Signe est devenu son marin / Et le Commandement son capitaine Et à la place d'une étoile, c'est la Volonté / Qui la fit naviguer jusqu'au port.

Par l'ancre de la Foi / Sa course a été liée

Et la Grâce a demeuré en elle / à la place du vent.

Ailleurs, Éphrem présente le Christ comme l'antitype de Noé, capitaine de l'arche qui mène le navire au calme ${ }^{93}$ :

Ô capitaine qui a dompté la mer enragée / ton bois glorieux est un signe Qui est devenu l'aviron du salut / ton vent de merci a soufflé, le navire s'est dérouté

de la mer enragée vers Le Havre de paix.

Béni soit celui qui est devenu le capitaine de sa propre âme / et a préservé et déchargé son trésor !.

88. Van Rompay, « Le commentaire sur Gen - Ex. 9,32», p. 58 T, 74 V.

89. Narsaï, memrā II, v. 255-265.

90. Sur l'imagerie du navire et du marinier très répandue dans la tradition syriaque, voir Robert Murray, Symbols of Church and Kingdom. A Study in Early Syriac Tradition, Cambridge : CUP, 1975, p. 249-253.

91. C1234, I, p. $42 \mathrm{~T}, 30 \mathrm{~V}$.

92. Narsaï, memrā II, v. 519-524.

93. Éphrem, HVirg 31, 15 (CSCO 223/Syr 94, p. 116). 
Ailleurs encore le Christ est présenté comme le pilote que la ville de Nisibe prie pour qu'il la mène à bon port et au repos (nwh) de la paix, alors qu'elle est soumise aux assauts des Perses ${ }^{94}$ : «Ô pilote de cette arche, / Sois mon navigateur sur la terre sèche! / Tu l'as fait reposer au port de la montagne, / Donne-moi le repos au port de mes murailles ».

\section{L'arche type de l'église}

L'arche est comme dans la tradition grecque ou latine le symbole de l'Église, refuge des âmes : «L'arche aussi avec ses animaux, / dans son type, a regardé vers notre Seigneur / qui allait bâtir l'Église sainte / dans laquelle les âmes seraient abritées ${ }^{95}$. Noé dans l'arche de bois représente aussi le mystère de l'incarnation : « Dieu a placé Noé dans l'arche de bois de même qu'il a placé Dieu dans le temple de sa chair ${ }^{96}$. Narsaï évoque l'arche comme un lieu d'emprisonnement mais aussi comme une tombe préfigurant celle du Christ : «Le 17e (jour) / la Justice les enterra / et le $27^{\mathrm{e}}$ de Iyar / la Grâce les ressuscita $»^{97}$.

Mais la tradition syriaque présente aussi une interprétation originale de l'arche comme un type de l'église en tant que bâtiment. C'est La Caverne des trésors qui offre la comparaison la plus explicite et la plus détaillée ${ }^{98}$ : Noé porte le corps d'Adam, ses fils - ou Sem seul - les trois offrandes de l'or, la myrrhe et l'encens qu'Adam avait emportées de la bordure du Paradis et les place à l'Orient de l'arche. Le corps d'Adam est placé au milieu de l'arche et les offrandes au-dessus - comme sur un autel. Le corps d'Adam préfigure ainsi le bêma au centre des églises syriaques : le corps d'Adam sert à marquer la séparation entre hommes et femmes de la famille de Noé dans l'arche, comme le bêma dans les églises de

94. Éphrem, CNis I, 3.

95. Éphrem, HNat, 1, 45, p. 6.

96. Éphrem, CGen Arm 4, p. 68 T, 63 V.

97. Narsaï, memrā II, v. 705-708.

98. Cav. 17, 14-15 (Testament de Lamech), 18, 3-5. Voir F. Briquel Chatonnet, «Les églises dans les textes », in Les églises en monde syriaque, Ead. (éd.), Paris : Geuthner, 2013 («Études syriaques », 10), p. 11-40. Sur le bêma, voir Jean-Pierre Sodini, "Archéologie des églises et organisation spatiale de la liturgie, dans Les liturgies syriaques, F. Cassingena-Trévedy \& I. Iurasz (éd.), Paris : Geuthner, 2006 («ÉS » 3), p. 229-266. 
tradition syriaque marque la séparation entre les sexes, les hommes étant à l'est et les femmes à l'ouest.

Puis au coucher du soleil, Noé entra dans l'arche, lui et ses fils du côté de l'Orient de l'arche, sa femme et les femmes de ses fils, du côté de l'Occident. Et le corps d'Adam fut placé au milieu de l'arche. Car tous les mystères de l'Église étaient représentés en elle. C'est pourquoi les hommes se tiennent dans l'église à l'Orient, et les femmes, à l'Occident, de manière à ce que les hommes ne voient pas le visage des femmes, ni les femmes le visage des hommes. C'est ainsi aussi qu'à l'intérieur de l'arche les hommes s'installèrent à l'Orient et les femmes à l'Occident. Et le corps d'Adam fut placé au milieu tout comme le bêma $a^{99}$.

La Caverne des trésors ${ }^{100}$ dans un testament oral de Noé à son fils Sem développe la typologie du corps d'Adam comme type du corps du Christ. Noé demande à Sem, une fois qu'il sera mort, d'aller secrètement prendre dans l'arche le corps d'Adam, d'emporter du pain et du vin et de se faire accompagner par Melchisédech, afin qu'il assure le service devant le corps d'Adam, déposé au centre de la terre. L'ange du Seigneur doit les accompagner pour leur montrer le lieu de la sépulture d'Adam au centre de la terre, là d'où viendra le salut (par la Croix du Christ qui sera érigée en ce même endroit, le Golgotha). Le corps d'Adam au centre de l'arche préfigure donc le Christ au tombeau. Toujours selon La Caverne des trésors, Dieu aurait aussi prescrit à Noé de fabriquer pour l'arche une simandre en bois afin d'appeler trois fois par jour les hommes à se réunir, comme la simandre dans les églises appelle à la prière.

Quand il évoque la liesse du dimanche pascal, Éphrem fait un parallèle entre les chants alternés à l'église des fils et filles de l'Alliance (forme syriaque de proto-monachisme) et les chants des hommes et des femmes chastes dans l'arche, types de la joie pascale. La dimension de la chasteté est rappelée ici au travers de l'allusion aux «fils et filles de l'Alliance » qui étaient consacrés pour le service de l'église, notamment pour les chants :

Voici la Fête radieuse : / Ce n'est que bouches et lèvres bées ! (...)

Les chants sacrés, les chants d'église / se mêlent aux tonnerres de Dieu (cf. Ex 19, 19)...

Ainsi dans l'Arche jubilaient / toutes les voix, toutes les bouches ; C'était dehors flots redoutables, / chants agréables au dedans ;

99. Cav. $18,2-6$, p. 52 V.

100. Cav. 23, p. 64-67. 
En duo (cf. Gn 6, 20) les langues chantaient / avec ensemble, purement. Là, se dessinait notre Fête / où hommes vierges et femmes vierges

Célèbrent par des chants, saintement, / la gloire du Seigneur de l'Arche ${ }^{101}$.

\section{Déluge et CATASTRophes NATURELles ou POLITIQUeS}

L'image du déluge et l'histoire de Noé ont pris un sens particulier pour les populations chrétiennes de Mésopotamie du Nord qui se trouvaient sur les lieux mêmes où l'arche était censée s'être arrêtée et qui étaient soumises périodiquement à des vagues d'attaques de la part des Perses sassanides puis des Arabes, des Turcs ou des Mongols. L'image du déluge fut donc lue comme un type des catastrophes naturelles et politiques qui frappaient la région. En 350 , le troisième siège de la ville de Nisibe, à la frontière entre les empires romain et perse, fut pour Éphrem, qui résidait dans la ville, l'occasion de filer la métaphore du déluge puisque les Perses détournèrent les eaux du fleuve Mygdonius contre les remparts. Le premier memrā Sur Nisibe, où la ville est personnifiée et s'exprime à la première personne, établit un parallèle entre sa situation et celle de l'arche sur les flots : « Voici que les tempêtes me bouleversent, / et je considère l' arche bienheureuse / car elle n'était cernée que par les vagues / moi, remblais, flèches et vagues me cernent de toutes parts $»^{102}$. La ville établit un parallèle entre Noé soumis aux vagues, à l'extérieur de l'arche, et aux animaux sauvages, à l'intérieur, et ses propres habitants : «Écoute et évalue ma comparaison avec Noé / Et si ma souffrance pèse moins que la sienne, / Que ta grâce égalise notre rédemption! / Car voici que mes enfants tiennent bon à sa ressemblance, /Entre enragés et rapaces. / Mets en paix avec moi, Seigneur, le dedans / Et abaisse devant moi le dehors $»^{103}$.

Nisibe insiste sur le fait que ce sont ses péchés (ceux de ses habitants) qui ont conduit au châtiment par les eaux, mais amèneront aussi la repentance et le pardon :

Au moyen de l'impur [le shah de Perse] tu as rassemblé les eaux pour l'absolution de mes propres péchés

101. Éphrem de Nisibe. Hymnes pascales, 2-4, Paris : Le Cerf, 2006 (« Sources chrétiennes », 502), p. 290-291, trad. François Cassingena-Trévedy.

102. Éphrem, CNis $1,3$.

103. Éphrem, CNis 1, 11, 1-7. 
Non pour m'absoudre en me plongeant en elle, mais pour me corriger en me terrifiant par elles. car les vagues éveillent la prière, laquelle lavera mes péchés.

La contemplation pleine de repentance est devenue pour moi comme un baptême.

La mer, Seigneur était destinée à me submerger : que la miséricorde submerge par elle les péchés.

La ville assiégée prie pour être une arche qui puisse sauver ses habitants. La situation des sièges où les habitants entrent dans la ville puis en ressortent est assimilée à celle des rescapés entrés dans l'arche et qui en sont ressortis ${ }^{104}$ :

Tu avais construit l'arche par miséricorde / pour y sauvegarder tous les rescapés.

Pour ne pas stériliser la terre par colère / ta grâce a fabriqué une terre de bois :

Tu as vidé l'une dans l'autre, / tu as remplacé l'une par l'autre.

Mon territoire à moi, à trois reprises / a été vidé et rempli. [allusion aux trois sièges par les Perses]

À présent c'est à moi que les vagues donnent l'assaut / pour supprimer le reste réfugié en moi.

Dans l'arche tu avais préservé un reliquat, /en moi aussi, Seigneur, préserve un levain.

L'arche a enfanté sur la montagne, / Que j'enfante sur mon territoire mes assiégés !

Parce qu'elle a été un refuge pour le petit reste des hommes, l'arche est invoquée comme image de la protection contre les forces déchaînées. Plus largement ses restes que l'on pensait toujours sur le mont où elle avait atterri ${ }^{105}$ devinrent des éléments de protection. L'arc-en-ciel même est évoqué par Éphrem comme le symbole d'une arme contre le déluge d'eau (des Perses) autour de la ville de Nisibe et est associé aux sacrifices de Noé, avant et après le déluge. L'arc n'est pas seulement un signe de l'alliance et de la promesse que la terre ne serait plus détruite mais une arme contre le déluge qui assaille la ville et un type de la croix du Christ, protectrice et salvifique :

Dieu de miséricorde, tu as donné satisfaction à Noé / qui lui-même avait donné satisfaction à ta miséricorde.

Il a offert des sacrifices et mis fin au déluge. / Il a présenté des offrandes et reçu une promesse.

104. Éphrem, CNis 1, 6.

105. Narsaï dit qu'elle fut cachée, afin que les hommes ne pussent en faire mauvais usage (memrā II, v. 840). 
Par la prière et le parfum il t'a plu / Par des serments et l'arc tu lui as fait grâce.

Dès lors que le déluge s'efforce / d'endommager la terre, (...)

L'arc s'étend à son encontre / pour le chasser et réconforter la terre

Que ton couple de signes nous préserve / moi, ta croix, Noé ton arc.

Que ta croix fende les eaux / comme ton arc avait mis fin au déluge de pluie ${ }^{106}$.

Les hymnes de Giwargis Warda (Église de l'est), au XIII ${ }^{\mathrm{e}}$ siècle, montrent comment l'épisode du Déluge a été intégré avec d'autres récits bibliques de destruction dans la grande fête de l'Église de l'Est que sont les Rogations des Ninivites. Fondée sur le livre de Jonas, cette fête commémorait la repentance des Ninivites qui avait permis de sauver leur ville et prenait une tonalité particulière pour les Syriaques orientaux qui vivaient dans cette même région de Mésopotamie (Ninive) où est situé le livre biblique de Jonas. La liturgie rassemblait des hymnes concernant aussi bien les catastrophes évoquées dans la Bible - mission de Jonas (hymnes 23,24), Déluge (hymne 53), déluge de feu de Sodome (hymne 22) - que des événements catastrophiques contemporains de l'auteur (hymnes 54-57) ${ }^{107}$. Cet épisode biblique a donc pris une valeur typologique particulière dans le contexte des guerres romanoperses $\mathrm{du} \mathrm{IV}^{\mathrm{e}}$ siècle dans la zone frontière où se situait Nisibe et plus largement des événements dramatiques, politiques et naturels, dans la région et n'a cessé d'être repris ensuite.

\section{LA SORTIE DE L'ARCHE}

Dans l'arche, la qaddishutā s'appliquait à tous les êtres vivants, mais la sortie de l'arche est marquée par l'injonction de croître et de multiplier ${ }^{108}$ :

Dieu dit à Noé : "Sors, toi et ta femme, vos fils et les épouses de vos fils". Ceux que Dieu avait fait venir en solitaires, pour

106. Éphrem, CNis 1, 1-2.

107. Anton Pritula, «The Wardā hymnological Collection», Scrinium 9 (2013), Patrologia Pacifica tertia, p. 329.

108. Éphrem, CGen VI, 12, trad. S. Brock, L'œil de lumière, p. 158 ; CSCO, p. $61 \mathrm{~T}, 49 \mathrm{~V}$. 
garder la qaddishuta dans l'arche, il les fit sortir en couples, pour se multiplier et procréer en abondance. Il dit aussi au sujet des animaux qui avaient gardé la qaddishuta dans l'arche : "Sortez avec tous les animaux qui étaient avec vous... et laissez-les donner naissance être féconds et se multiplier sur la terre".

La sortie de l'arche est présentée par Éphrem comme un accouchement : «L'arche a enfanté sur la montagne » ${ }^{109}$, donnant naissance à un peuplement nouveau de la terre. C'est aussi un déménagement, qui vide l'arche de ses types, réalisés dans le Christ :

Dans la Loi sont ses symboles, / Et dans l'arche sont ses types, Chacun témoignant pour l'autre. / Comme les recoins de l'arche Ont été déménagés, / Ainsi ont été vidés

Les types de l'Ecriture. / En venant il réalise

Les symboles de la Loi, / Dans son Église il achève / Les types présents dans l'arche ${ }^{110}$.

Éphrem emploie aussi l'image du navire que l'on décharge, type de celui qui a préservé son âme ${ }^{111}$ : "Béni soit celui qui est devenu le capitaine de sa propre âme / et a préservé et déchargé son trésor ! ». Narsaï la présente comme une libération de prison et comme une résurrection du tombeau au mois du printemps ${ }^{112}$, type du Christ ressuscité à Pâques. Selon La Caverne des trésors, Noé avait envoyé deux colombes symbolisant l'ancienne et la nouvelle Alliance, l'une se posa sur le peuple obstiné, l'autre sur les nations purifiées dans l'eau du baptême ${ }^{113}$. Selon NarsaII, c'est un corbeau avide et une colombe qui furent envoyés ${ }^{114}$.

\section{Le rameau d'olivier}

Le rameau d'olivier rapporté à Noé par la colombe est aujourd'hui associé à l'idée de paix mais il est interprété dans la tradition syriaque comme symbolisant l'huile dont la source est le Christ, qui est à la fois l'oint et l'Olive ${ }^{115}$. L'onction pré-baptismale, du corps entier

109. Éphrem, CNis 1, 6, 13.

110. Éphrem, Fid 49, 4-5, trad. S. Brock, L'œil de lumière, p. 65.

111. Éphrem, HVirg 31, 15 (CSCO 223/Syr 94, p. 116).

112. Narsaï, memrā II, v. 701-708.

113. Cav. 19.13.

114. Narsaï, memrā II, v. 653.

115. Brock, « Baptismal themes », p. 343 citant B IV, p. 49. 
ou sur le front, constituait avant l'immersion dans l'eau l'élément central du baptême dans la tradition syriaque ancienne : le rušmā ou « marque » $(E z$ 9, 4), qui se faisait avec de l'huile d'olive. Elle fut cependant, à partir $\mathrm{du} \mathrm{IV}^{\mathrm{e}}-\mathrm{V}^{\mathrm{e}}$ siècle, progressivement complétée ou remplacée par une onction post-baptismale par le myron, comme dans la tradition grecque ${ }^{116}$.

L'image de l'onction n'est pas évoquée directement par Jacques de Saroug, ni non plus par le premier madrashā Sur Nisibe d'Éphrem où il est question de la joie qu'elle apporte, mais aussi de son rôle de guérison du péché (l'huile était, et est encore aujourd'hui, un élément important pour la guérison de l'âme et du corps dans la médecine traditionnelle) : «L'olivier, dont l'huile fait luire les visages / a réjoui les faces par son rameau (...) / Par l'olivier tu as réjoui les assiégés [de l'arche] / par la colombe, tu as envoyé un médecin / aux infirmes que tourmentaient les vagues $»^{117}$.

Dans le madrashā 7 Sur la Virginité en revanche, consacré à l'huile et à ses symboles, Éphrem établit une comparaison entre les eaux du baptême et celles du déluge qui engloutissent le péché, tandis que la branche d'olivier rapportée à Noé représente la compassion divine et le type de la résurrection ${ }^{118}$ : impurs

L'huile [d'olive] efface les péchés, comme le déluge a effacé les car le déluge, tel le Juste, en justice a effacé les mauvais (...) (...)

et l'huile, à la manière du Bon, a effacé les péchés dans le baptême ${ }^{119}$

[l'olive] par sa branche encore a servi, grâce à la colombe, Noé son type [le type du Christ] (...)

Par ses branches, il a peint le symbole de la victoire,

et comme la mort a dégorgé (le Christ), le déluge a dégorgé la branche d'olivier.

Le madrashā Sur la Foi est celui qui établit la typologie la plus explicite entre le déluge et le baptême, par les eaux, mais aussi par

116. S.P. Brock, "The Transition to a Post-Baptismal Anointing in the Antiochene Rite ", in The Sacrifice of Praise : Studies on the Themes of Thanksgiving and Redemption in the Central Prayers of the Eucharistic and Baptismal Liturgies in Honour of Arthur Hubert Couratin, Bryan Douglas Spinks (éd.), Roma : Edizioni Liturgiche, 1981 ("Ephemerides liturgicae, Subsidia", 19), p. 215-225.

117. Éphrem, CNis 1, 4, 11-12 et 7, 2-4.

118. Éphrem, HVirg 7, 13, 4 et 6.

119. Éphrem, HVirg 9, 2-3 et 5. 
l'huile d'onction. Cette strophe reprend plusieurs des images déjà évoquées : l'arche est le type de l'Église, le Christ en étant timonier, la colombe est le type de l'Esprit et par le rameau d'olivier préfigure l'huile de l'onction baptismale ${ }^{120}$ :

L'arche a tracé, par sa course, / le signe de son sauveur, la Croix de son timonier, / le bois du navigateur, descendu pour nous construire / une Église sur les flots. Par le triple nom il sauve / ceux qui habitent dedans et remplaçant la colombe, / l'Esprit livre son onction.

\section{D'une montagne à l'autre : une nouvelle géographie post-diluvienne}

Les commentateurs syriaques présentent le monde d'après le déluge comme un second monde, renouvelé grâce à Noé : « Noé fut protégé des eaux diluviennes afin que par lui, se renouvelle un second monde $»^{121}$. «Il prit femme, afin d'avoir une descendance à partir de laquelle le monde serait rétabli et de devenir le père des pieux et des justes ${ }^{122}$. Ses fils sont associés à ce renouvellement des générations et du monde : «Il leur donna des femmes de la descendance des justes, afin que, par eux, soit gardée une descendance sur la surface de la terre, et que, par eux, le monde soit rétabli $»^{123}$.

L'histoire de l'humanité primordiale est présentée comme celle de l'éloignement progressif du Paradis commencée avec l'expulsion d'Adam et Ève. Alors que les fils de Seth vivaient encore sur les flancs de la montagne qu'est le Paradis dans la tradition syriaque ${ }^{124}$, ils descendirent des abords du Paradis, attirés

120. Éphrem, Fid 49, 4.

121. Aphraate, Dem. 23, 4, Parisot, II, 13 ; Pierre, II, p. 885 et Dem. 13, 7, Parisot, I, 559 ; Pierre, II, p. 598.

122. Aphraate, Dem. 13,6, Parisot, I, 556 ; Pierre, II, p. 597.

123. Aphraate, Dem. 13,5, Parisot, I, 552, Pierre, II, p. 595.

124. Sur la montagne du Paradis dans la tradition syriaque, voir Murray, Symbols of Church and Kingdom, p. 306-310 ; Gary A. Anderson, « The Cosmic Mountain : Eden and Its Early Interpreters in Syriac Christianity », in Genesis 1-3 in the History of Exegesis : Intrigue in the Garden. Gregory Allen Robbins (éd.), Lewiston - Queenston : Edwin Mellen, 1988, p. 187-224 ; Martin Lang, «Utopie und mythische Geographie - Mesopotamisches Erbe in der syrischpatristischen Tradition am Beispiel des Paradiesesberges und des Landungsplatzes der Arche », in Akten des 5. Symposiums zur Sprache, Geschichte, Theologie und Gegenwartslage der syrischen Kirchen (V. Deutsche Syrologentagung), Rainer M. Voigt (éd.), Aachen : Shaker Verlag, 2010 ( Semitica et Semitohamitica Berolinensia », 9), p. 69-85; Sergey Minov, «Regarder la montagne sacrée : 
par les filles de Caïn, dans la plaine. C'est au sommet de cette montagne du Paradis qu'est située la caverne des trésors où est enterré Adam ${ }^{125}$ selon La Caverne des trésors. Ce texte dit que Noé, sa femme, ses fils et ses belles-filles étaient les seuls à n'être pas descendus de la montagne du Paradis «parce qu'ils n'avaient pas engendré de fils avant le Déluge », c'est-à-dire ne s'étaient pas corrompus avec les filles de Caïn ${ }^{126}$. Le texte fait entendre les lamentations de Noé et de ses fils, leurs adieux aux arbres et aux pierres de la sainte montagne, leurs pleurs de devoir en descendre pour entrer dans l'arche ${ }^{127}$. Noé et les siens furent les derniers à vivre sur les flancs du Paradis. Après le déluge, les hommes ne furent plus dignes d'habiter à proximité.

La question s'était posée de savoir si la création tout entière avait été engloutie par le déluge. Certains rabbins pensaient que la Palestine avait flotté ; les Samaritains pensaient que le mont Garizim n'avait pas été recouvert ${ }^{128}$. La position d'Éphrem était que le Paradis était la seule montagne à n'avoir pas été recouverte par les eaux du déluge : au contraire, les eaux du déluge étaient venues baiser les pieds du Paradis avant d'engloutir les autres montagnes; Selon La Caverne des trésors, l'arche fut bénie par le Paradis ${ }^{129}$.

Chez Éphrem comme dans La Caverne des trésors ${ }^{130}$, les hommes après le déluge ne sont plus dignes d'être voisins du Paradis ou d'habiter sur la montagne du Paradis, aussi l'arche se posa sur une autre montagne ${ }^{131}$ :

Quand Adam pécha, / Dieu l'expulsa du Paradis, mais dans sa grâce il lui accorda / la terre basse au-delà et l'installa dans les vallées. /Mais comme l'humanité même là continuait à pécher,

représentations du Paradis dans la tradition chrétienne syrienne », in Mondes clos. Cultures et jardins, Daniel BARBu, Philippe Borgeaud, Mélanie Lozat \& Youri Volokhine (éds), Gollion : Infolio, 2013 (« Asdiwal, Supplément », 1), p. 241-269, 367-374.

125. Cav. 6, 21.

126. Cav. 14,3 .

127. Cav. 17, 18-20.

128. Cf. Levene, Early Syriac Fathers, p. 187 citant Ber. R. 32, 10.

129. Cav. 19, 3-4.

130. Cav. 16I, 18 et 19, 6 .

131. Sur les montagnes sacrées, Mircea Eliade, Le mythe de l'éternel retour, Paris, 1969, p. 24-30. 
et comme ils étaient indignes / d'être voisins du Paradis,

Dieu ordonna que l'arche / les rejetât sur le mont Qardu ${ }^{132}$.

La tradition antique la plus connue est que l'arche s'était arrêtée en Arménie, sur le mont Ararat (identifié avec le mont Masis en Arménie actuelle) ${ }^{133}$. En syriaque cependant s'est développée une autre version, qui remonte à la traduction de la Pešitta ${ }^{134}$. Contrairement à l'hébreu et à la Septante, la Pešițta en Gen 8, 3-4 et en Isaïe 37, 38 (mais pas en 2 Rois 19,37) porte en effet que c'est sur le mont Qardu (Ğūdi Dagh) que l'arche s'était posée, c'est-à-dire dans le nord de l'Iraq ${ }^{135}$. Or cette identification, déjà connue de Flavius Josèphe (Ant. I, 93), apparaît aussi dans les Targums palestinien et babylonien sur la Genèse et dans le Targum Jonathan sur les Prophètes dont le texte hébreu a pourtant Ararat ${ }^{136}$. Le lieu où fut fondée la première ville après le déluge est selon La Caverne des trésors Tamanon, dont le nom est formé sur la racine sémitique « huit», d'après les huit personnes sorties de l'arche. Un village de ce nom est connu au nord du mont Ğūdi ${ }^{137}$. Un monastère syriaque, dit « monastère de l'arche », y fut bâti et devint un lieu de pèlerinage jusqu'au XIX ${ }^{\mathrm{e}}$ siècle $^{138}$.

Narsaï développe cette géographie en faisant de l'arche un pont entre le monde pré-diluvien et le monde post-diluvien qui est le centre de la terre et qui n'était pas connu des hommes avant le déluge et n'avait pas été foulé par les animaux : «D'un lieu proche de l'Eden / Elle [l'arche] embarqua au début de sa course / Et conclut son voyage/ Au sommet des montagnes de Qardu ${ }^{139}$. Les générations pré-diluviennes vivaient de l'autre côté de l'océan qui entoure la terre :

Jusque-là, invisible / était le milieu de la terre pour les hommes.

La mer avait été une barrière devant eux / jusqu'à ce que le déluge vienne.

132. Éphrem, Par. 1, 10.

133. Voir Michael E. Stone, «Mount Ararat and the Ark» in Noah and his Books, p. 307-316.

134. Gen 8, 4. Cf Brock, Kronholm, p. 201, n. 95.

135. C'est aussi la version du commentaire du ms. Mingana 553 (Levene, Early Syriac Fathers, p. 188).

136. Sebastian P. Brock, « The Peshitta Old Testament : Between Judaism and Christianity », Cristianesimo nella storia 19.3 (1998), p. 483-502, p. 493 et id., « Jewish Traditions in Syriac Sources », Journal of Jewish Studies 30.2 (1979), p. 212-232 (p. 213-214).

137. Fiey, Nisibe, métropole syriaque orientale, p. 179.

138. Fiey, Nisibe, métropole syriaque orientale, p. 121-123 et 221.

139. Narsaï, memrā II, v. 545-549. 
Et le Signe brisa la barrière / et les transféra au centre.

Aux abords du Paradis / avaient vécu dix générations et la terre entière était vide / d'hommes et d'animaux.

Et c'était un lieu désolé (...) / C'est pour cette raison que la Grâce fabriqua l'arche / pour qu'elle serve de pont à la maison d'Adam et les transfère dans les espaces ouverts ${ }^{140}$.

Une géographie où la mer sépare le Paradis de la terre est habituelle dans la tradition chrétienne. Le monde post-diluvien n'est autre que le centre de la terre qu'entoure l'océan par-delà lequel se trouve le Paradis, à l'Orient. Ce qui est plus original, c'est l'idée que les hommes gagnèrent la terre grâce à l'arche qui pava le chemin qu'aucun homme n'avait foulé avant. Le second monde d'après le déluge est un monde nouveau, pas seulement l'ancien monde englouti redevenu sec. Narsaï établit un parallèle entre l'exode de l'arche et l'exode du peuple d'Israël vers la terre promise et avec la création du monde, événements qu'il situe « au mois des fleurs ${ }^{141}$. Les commentateurs chrétiens se sont particulièrement intéressés à la géographie nouvelle de l'implantation des hommes sur la terre après le déluge. La division de la terre entre les fils de Noé constitue en effet, avec les apports de la géographie ionienne le fondement de la géographie chrétienne. Cet aspect bien connu ne sera pas repris ici ${ }^{142}$.

\section{Le quatrième fils de Noé}

Face aux blancs du texte biblique sur les événements postdiluviens, les exégètes juifs et chrétiens se sont posé la question de savoir pourquoi Noé n'avait plus engendré après le déluge et quelle était la nature exacte du crime de Cham, qui avait conduit à la malédiction de Canaan, son fils. L'exégèse rabbinique de Gen 9.24 évoquait deux interprétations alternatives selon lesquelles ou bien Cham - ou alternativement un lion! - avait castré son père ou bien avait couché avec lui ${ }^{143}$. Cette castration est destinée à expliquer

140. Narsaï, memrā II, v. 555-565, 570-573.

141. Narsaï, memrā II, v. 739.

142. Pour la tradition syriaque, voir Witold Witakowski, « The Division of the Earth between the Descendants of Noah in Syriac Tradition », ARAM 5 (1993), p. 635-656. Jacques Marie Vosté, «La table ethnographique de Gen. X, d'après Mar Išo ‘dad de Merw (c. 850) », Le Muséon 59 (1946), p. 319-332. D. Machiela, «Noah Traditions », in Noah and his Books, p. 244-250.

143. Stephen Gero, "The Legend of the Fourth Son of Noah", Harvard Theological Review 73.1-2 (1980), p. 321-330 (p. 321-322). Koltun-Fromm, 
pourquoi ce fut le fils de Cham et non Cham lui-même qui fut maudit : Noé empêché d'avoir un autre fils, maudit la descendance de son fils et non son fils lui-même.

La tradition syriaque connaît toutefois un quatrième fils de Noé engendré après le déluge, qui joue un rôle dans l'histoire culturelle et religieuse de l'humanité : ce fils du nom de Yonțon aurait transmis à Nemrod la sagesse, la connaissance de l'astrologie et la révélation concernant Jésus-Christ ${ }^{144}$. Selon La Caverne des trésors, la révélation de Dieu à Adam fut transmise par voie orale jusqu'à Noé et le rôle de Yonțon, son dernier fils, aurait été de transmettre à Nemrod la sagesse et les révélations qui parvinrent ensuite aux Mages, qui, en lisant la révélation de Nemrod, comprirent l'économie du Christ et apportèrent les offrandes de l'or, la myrrhe et l'encens à l'Enfant ${ }^{145}$. Cet épisode se comprend dans le contexte probable de composition de La Caverne des trésors, en milieu syro-oriental, où les Mages étaient considérés comme les premiers à avoir évangélisé la Perse, à leur retour ${ }^{146}$.

La mention de ce quatrième fils a été reprise à La Caverne des trésors par L'Apocalypse du Pseudo-Méthode. Il est dit là que Noé envoya ce fils vers l'Est et qu'il s'établit près de la mer de feu du Soleil. Il reçut de Dieu des révélations de sagesse et envoya à Nemrod une lettre dans laquelle il prédisait le triomphe des descendants de

«Aphrahat and the Rabbis », p. 65-67; Alexander Toepel, «Yonton Revisited : A Case Study in the Reception of Hellenistic Science within Early Judaism », Harvard Theological Review 99. 3 (2006), p. 235-245, argumente en faveur de l'assimilation entre Yonțon et le Yoqtan de Gen 10.25, suivant Gero et Ri, Commentaire, p. 341-357, qui plaidaient pour une origine juive du personnage, contre Clemens Leonhard, «The Lord's Prayer Between Christian Ethics and Liturgy : Its Interpretation in Theodore of Mopsuestia's Catechetical Homilies and the Reception by Later East-Syrian Authors », in Identität durch Gebet. Zur gemeinschaftsbildenden Funktion institutionalisierten Betens in Judentum und Christentum, A. Gerhards, A. Doeker \& P. Ebenbauer (éds), Paderborn - München - Wien - Zürich (« Studien zu Judentum und Christentum »), 2003, p. 335-367, suivant Witakowski, « The Division of the Earth (cit. n. 143), p. 641 et 648 qui pensent que le personnage de Yonțon a été inventé par l'auteur de la Caverne.

144. Cav. 27, 9-11, p. 80-81 V. Voir Gero, « The Legend of the Fourth Son of Noah ».

145. Cav. $45,11$.

146. Sur les douze rois mages, voir par ex. Muriel Debié, «Suivre l'étoile à Oxford, inédits sur la venue des Mages », in Malphono w-Rabo d-Malphone : Studies in Honor of Sebastian P. Brock, George A. Kiraz (éd.), Piscataway, 2008 («Gorgias Eastern Christian Studies », 3), p. 111-133. 
Japhet sur ceux de Cham contre lesquels ils s'étaient alliés. Par cet intermédiaire, l'histoire de Yonțon gagna la chronique de Michel le Syrien : "Méthode dit à propos de Ionițan qu'il fut engendré par Noé après le Déluge (...) et qu'il alla habiter là où le soleil se lève ; il trouva le nombre des étoiles $»^{147}$. Ce passage reprend donc le lien de Yonton avec l'astronomie et cherche manifestement à lui assigner une place sur la terre qui ne fut répartie qu'entre les trois premiers fils de Noé.

\section{L'ivresse de Noé}

Une interprétation positive est généralement donnée à l'épisode gênant de l'ivresse de Noé. La Caverne des trésors la commente en en faisant le symbole du crucifiement par la reprise, traditionnelle dans l'exégèse chrétienne du psaume 78, 65 : «Le Seigneur s'est éveillé comme un dormeur et comme un homme terrassé par le vin ». Noé est le type du Christ par son «éveil » de l'ivresse, mais aussi par la malédiction contre Canaan : il s'est éveillé de son sommeil et a maudit Canaan de même que le Messie s'est levé de la maison des morts, a maudit le peuple juif et l'a dispersé parmi les peuples. La dimension anti-judaïque est centrale dans cette interprétation. Noé dispersa aussi selon La Caverne la descendance de Canaan parmi tous les peuples, c'est pourquoi les Égyptiens sont asservis et errent sur la terre ${ }^{148}$. À partir du chapitre 16, en effet, la malédiction de Cham est transférée aux Égyptiens qui sont englobés dans les Cananéens.

La malédiction contre Canaan et non contre Cham est interprétée par Éphrem comme étant destinée à éviter que tous les descendants de Cham ne soient maudits : Canaan l'a été, mais Cush, Égypte et Put, les trois autres fils de Cham ne l'ont pas été parce qu'ils n'avaient pas imité leur père comme Canaan ${ }^{149}$. C'est à cause de leur justice que leur père Cham ne fut pas maudit. Il explique aussi qu'il ne faut pas comprendre quand il est question du plus jeune fils de Noé qu'il s'agit de Cham car celui-ci était le cadet et non le benjamin, mais de Canaan qui était petit quand il vit la nudité de

147. MS II, 8 , IV, p. 17 T, I, p. 32 V.

148. Cav. 21, 21-26.

149. Éphrem, CGen Arm 4, p. 81 T, 72 V. 
Noé. Cham s'était contenté de rire et d'aller raconter ce que son fils lui avait dit ${ }^{150}$.

D'autres exégèses de ce passage sur l'ivresse de Noé ont été développées. Ainsi Éphrem dans le premier Hymne sur la Nativité établit un parallèle entre la nudité de Noé et celle d'Adam et propose l'interprétation selon laquelle les deux fils qui ont caché la nudité de leur père attendaient le Fils unique qui viendrait couvrir la nudité d'Adam, enivré d'orgueil, et délivrer Canaan de la servitude du péché ${ }^{151}$. Cette exégèse se distingue de celle de La Caverne des trésors par exemple qui voit dans l'ivresse de Noé un type de la crucifixion et n'interprète pas de manière symbolique la servitude comme le fait Éphrem qui parle de Canaan, représentant le peuple juif, comme asservi au péché et donne ainsi une tonalité antijudaïque.

La plupart des commentateurs ont cherché à exonérer Noé de son ivresse et ont tiré une interprétation moralisante de l'épisode. Selon Narsaï, Noé fut ivre parce qu'il ne savait pas faire usage de la boisson, mais son ivresse n'est pas présentée de manière positive : elle l'a avili et Cham le licencieux a pu ainsi se moquer de lui ${ }^{152}$. Cet épisode est une occasion pour Narsaï comme plus tard au $\mathrm{VII}^{\mathrm{e}}$ siècle pour Martyrius-Sahdona, un auteur syro-oriental, d'encourager à s'abstenir de boire du vin, dans l'idée de promouvoir les pratiques ascétiques et une conduite morale ${ }^{153}$. Éphrem pour sa part présente une version proche des targums en ce qu'il précise que Noé après s'être déshabillé s'était endormi, ce qui n'est pas dans le texte biblique, et surtout en ajoutant que Cham avait informé ses frères de la nudité de leur père dans la rue. Ce dernier élément est destiné à montrer que plusieurs années s'étaient écoulées entre la sortie de l'arche et le moment où Noé avait bu du vin, suffisamment de temps pour que l'on ait construit des villes. Noé s'est enivré parce qu'il n'était plus habitué au vin et non parce qu'il avait abusé de la boisson.

150. Éphrem CGen VI, 9, p. 64 T, 51 V

151. Éphrem, HNat I, 23-26. Pour une étude des exégèses de Gen 9, 20-27, chez les Pères latins, grecs et syriaques, voir Minov, Syriac Christian Identity, p. 59-66.

152. Narsaï, memrā II, v. 831-836.

153. Voir Minov, Syriac Christian Identity, p. 61. 


\section{Conclusion}

Les aspects évoqués sont quelques îlots émergés de «la mer de symboles $»^{154}$ qui baigne les textes syriaques. L'un des principaux éléments qui font l'originalité de cette tradition est sans doute celui qui présente Noé comme un proto-ascète avant qu'il ne devienne un nouvel Adam à la tête d'une nouvelle création. La qaddishutā, l'abstinence de relations sexuelles, qu'il pratiqua jusqu'au moment de fabriquer l'arche et ensuite encore dans l'arche, est à rapprocher de certaines traditions juives mais dans une perspective ascétique et eschatologique proprement chrétienne et même proprement syriaque. La mise en parallèle des hommes et des femmes dans l'arche avec les fils et les filles de l'Alliance du christianisme syriaque, de même que l'image de l'arche comme type du bâtiment des églises syriaques avec bêma sont autant d'exégèses originales. Les eaux agitées du déluge comme type des eaux du baptême, le rameau d'olivier comme type de la chrismation pré-baptismale constituent autant de symboles sacramentaires. La course de l'arche en forme de croix, avec l'ange de Dieu ou le Christ comme timonier, les étages de l'arche symbolisant les trois niveaux du corps, de l'esprit et de l'âme en l'homme ne sont que quelques-unes des interprétations symboliques dessinées dans les textes.

Ce qui donne une force particulière à ces interprétations, c'est aussi que nombre des événements racontés dans la Bible se sont produits sur les lieux où vivaient les chrétiens de langue syriaque, tout particulièrement ceux d'Iran et d'Iraq. La géographie postdiluvienne telle qu'elle est décrite dans les différents textes, tournant autour des monts du Paradis et du Qardu, décentrée vers le nouveau monde terrestre entouré par l'Océan sur lequel s'acheva l'exode des rescapés de l'arche, constitue une lecture originale du monde fondée sur la traduction syriaque de la Bible inspirée des targums pour former une tradition propre au christianisme syriaque autochtone. Le rôle du $4^{\mathrm{e}}$ fils de Noé comme transmetteur du savoir à Nemrod (crédité par la tradition syriaque d'avoir fondé Édesse entre autres villes mésopotamiennes) puis aux Mages, premiers évangélisateurs de la Perse, participe de cette appartenance à une géographie autant qu'à une histoire locale du salut. L'amarrage de

154. Cf. Éphrem, HNis 39, 17. 
l'arche au mont Qardu devenu lieu de pèlerinage, l'utilisation de l'image du déluge dans le contexte des sièges de Nisibe au IV siècle puis des catastrophes politiques et naturelles encore au XIII ${ }^{\mathrm{e}}$ siècle témoignent de cette même proximité symbolique. Ce que l'histoire de Noé sous tous ses aspects révèle une fois encore, c'est la force de l'interprétation typologique - qu'elle soit naturelle, sacramentaire, biblique (de l'Ancien au Nouveau Testament) symbolique ou historique - à l'œuvre dans l'exégèse et la théologie syriaques.

muriel.debie@ephe.sorbonne.fr 